\title{
MORGOIL BEARING TECHNOLOGY UPGRADE AT TERNIUM SIDERAR HOT STRIP MILL*
}

Gabriel R. Royo'

Thomas C. Wojtkowski

Andres Esteban ${ }^{3}$

\begin{abstract}
This paper will cover a back up roll bearing technological upgrade, being implemented at the TERNIUM SIDERAR Hot Strip Mill (HSM), in San Nicolas, Buenos Aires, Argentina. This change was motivated by increased operating loads, which caused the original bearings to be outside the designed bearing rating. The problems were first identified by bearing seizures in some stands, and later followed by cracks forming in the back up roll neck areas due to fatigue and overload. MORGOIL engineers worked together with TERNIUM SIDERAR engineers in analysing the problem and to upgrade the mill with the newest and most economical technology. The upgrade consisted of changing the bearings to the latest generation MORGOIL bearing: the KLX, which within the same space, increases bearing capacity around $25 \%$. This was accomplished re-utilizing all chocks. The new bearing allowed for a re-design of the geometry of the back up roll neck, making it much stiffer than the original design, and eliminating fatigue failures. In addition, an upgrade to hydraulic mounting and dismounting using the MORGOIL $\circledast$ HB lock was also implemented, as well as changing to the newest MORGOIL® HD seals. With the MORGOIL $\AA$ KLX® upgrade, TERNIUM SIDERAR HSM increased load capacity, allowing them to roll products that were not even considered decades ago. Both older oil film bearings and roller bearing mills have been successfully upgraded while reusing existing chocks and in many cases rolls. Solutions are customized to the customer's equipment and goals.
\end{abstract}

Keywords: back-up roll bearings; bearing upgrades; mill upgrades; mill modernization.

1 Gabriel Royo, Mater in Engineering - University of Nebraska, Vice President - Metallurgical Services, Primetals Technologies US, Worcester MA, USA.

2 Thomas C. Wojtkowski, BSME - University of Massachusetts at Amherst \& MEME - Rensselaer Polytechnic Institute, Director of Engineering, Metallurgical Services Division (Flat Mill \& MORGOIL Bearings), Primetals Technologies US, Worcester MA, USA

3 Andres Esteban, Roll Shop Engineer, Ternium Siderar, Florencio Varela, Buenos Aires, Argentina. 


\section{INTRODUCTION}

The life of a rolling mill is very long, but technology that was state-of-the-art 10, 20, or 30 years ago has been surpassed. Contemporary bearing technology allows new mills to produce higher quality product at increased capacity and less cost than older mills. The purpose of this paper is to explain how upgrades can allow mills with older bearings to compete with new mills.

As a mill gets older advances in rolling technology makes it difficult for older mills to produce the same high quality product at the production levels of newer mills. TerniumSiderar and MORGOIL $\AA$ Bearings worked together in order to enable the HSM, using the latest technology, to achieve demanding levels of quality and reliability required by the flat steel market today.

\section{Case Study: Hot Strip Mill load capacity increase for rolling tougher materials}

Ternium-Siderar Argentina has an HSM with a capacity of 2.8 MTn annually. This HSM has four pusher furnaces and one walking beam furnace, a non-reversible roughing mill with 5 stands, a finishing mill with 6 stands (4 high), and two coilers plus services.

The Ternium-Siderar Argentina HSM has been in operation for over 50 years. Over that time, the operational requirements on equipment have continuously increased in order to meet the needs of the market, new products are higher strength and much more difficult to roll. Because of this, specific workloads on the mill have increased and in many cases, exceeded the original equipment ratings. For example, bridge grade $7640,4.75$ x 1500 , requires a rolling force of 2910 tons versus the 2600 ton original stand rating.

The original backup roll bearings on the HSM were MORGOIL 42"-90 TRT-X-TR bearings. These bearings have a long key between the sleeve and roll neck which was the state-of-the-art in the 1950's. Additionally, this bearing uses 1950's locking and sealing technology. All of these designs have since been superseded several times, allowing modern bearings to provide higher mill capacity with much better quality and more efficient operation.

Generally, the limiting point in a roll and bearing design is roll neck stress. When continuously overloaded and with the cyclical nature of the loading, fatigue cracks form at the high stress point in the neck - the neck fillet radius. When the crack becomes large enough, the roll neck suffers a catastrophic failure. This has happened numerous times causing serious loss of production, Figure 1. 


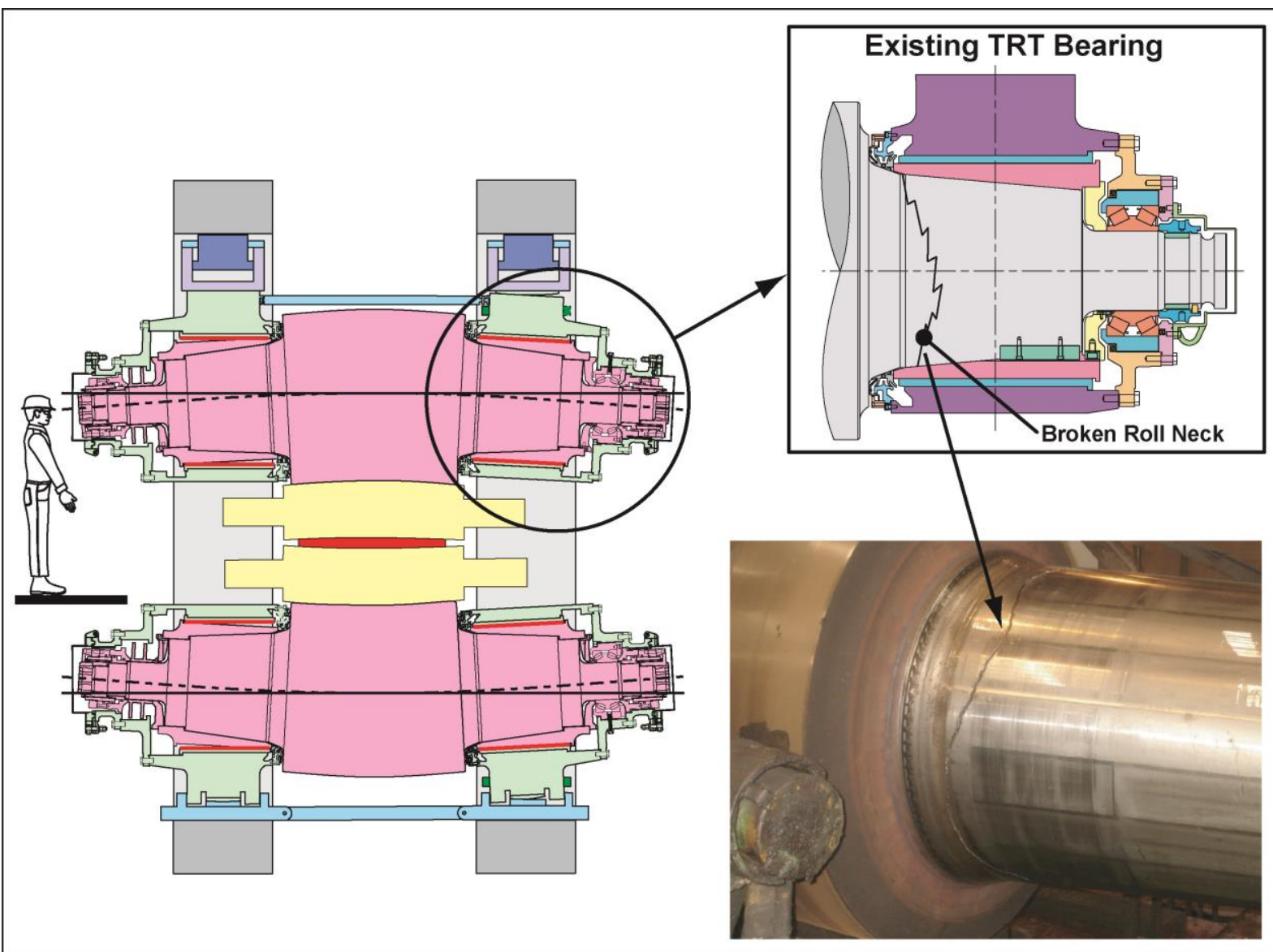

Fig. 1: Ternium HSM Roll Neck Failure

A load analysis was done for the mill, Figure 2. The mill had originally been specified to operate in the yellow shaded area of the curve, and was now operating well above it (the dashed lines). With very few modifications a 42"-86 KLX bearing could be fit into the existing chocks. This moved the operating range up to the blue area of the graph giving the mill extra capacity for future increases. The updated bearing would have a larger roll neck, Figure 3, reducing stress in the neck at the higher loads. The KLX bearing uses a new thin sleeve technology, allowing for a larger roll neck and increased capacity. The thin sleeve technology was developed through years of research and testing, it redistributes the bearing load over a larger area allowing for the increased capacity in a smaller size. 


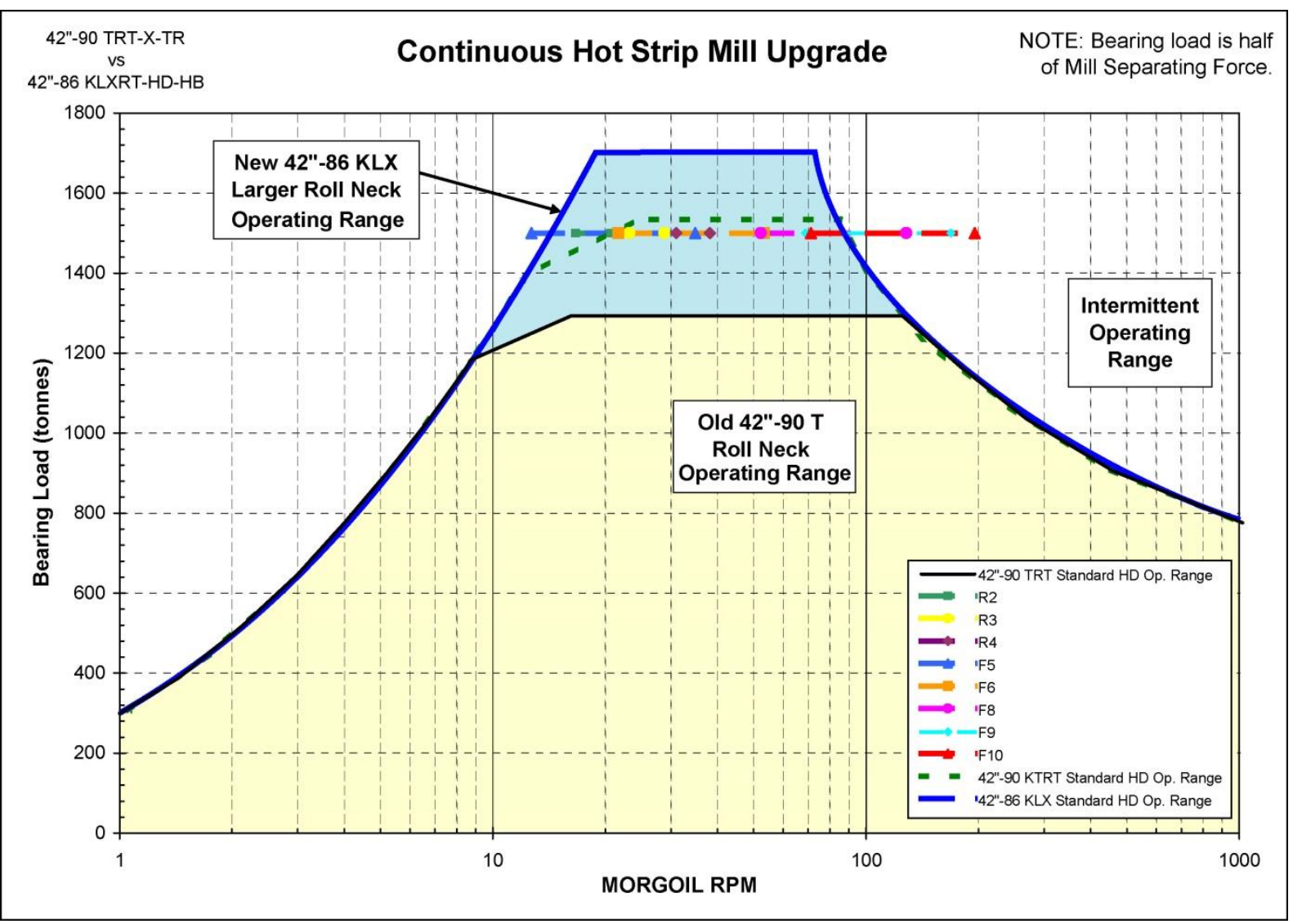

Fig. 2: Bearing Operational Comparison 


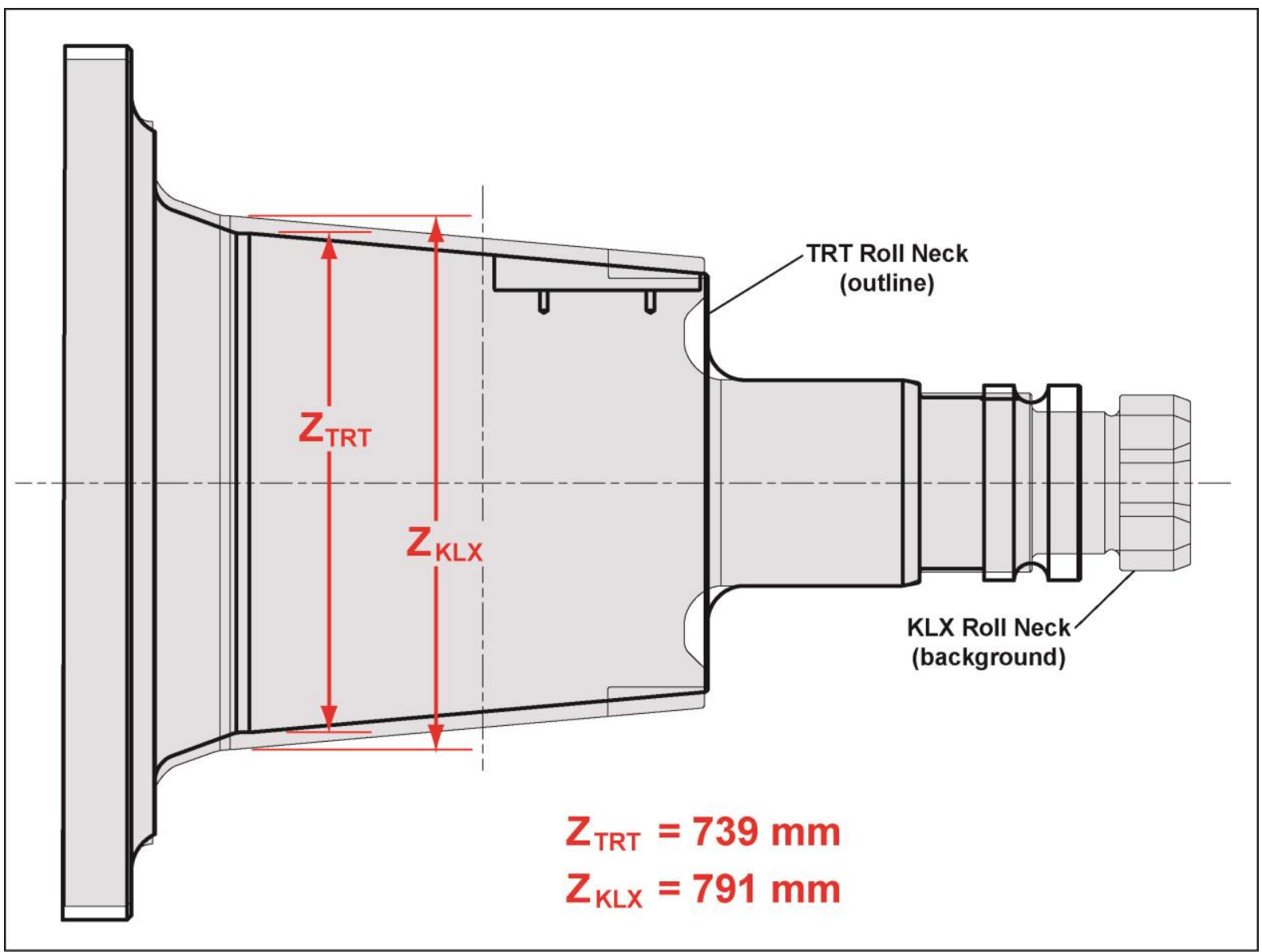

Fig. 3: Roll Neck Comparison

\section{Primary features of the complete upgrade}

The existing Chocks are used with minimal modification. The chock bores are machined slightly oversize to ensure that they are true.

The primary features of the bearing upgrade are shown in Figure 4.

- The old broken rolls are replaced with new rolls with larger necks, which are supplied to accommodate the KLX design.

- KLX Sleeves and Bushings result in the largest possible load capacity in the existing chock design.

- New Sleeve Ring accommodates the higher axial loads.

- New HD Neck Seal assembly with ground light metal ceramic sealing surfaces, vents, and drain-backs.

- The existing Chock End Plate and Thrust Bearing Assembly are used, saving considerable time and expense.

- A new HB Lock to complete the conversion.

The combination of the above improvements result in an upgraded bearing that meets the most modern performance standards while using much of the existing chock and exterior bearing equipment, minimizing capital expense. 


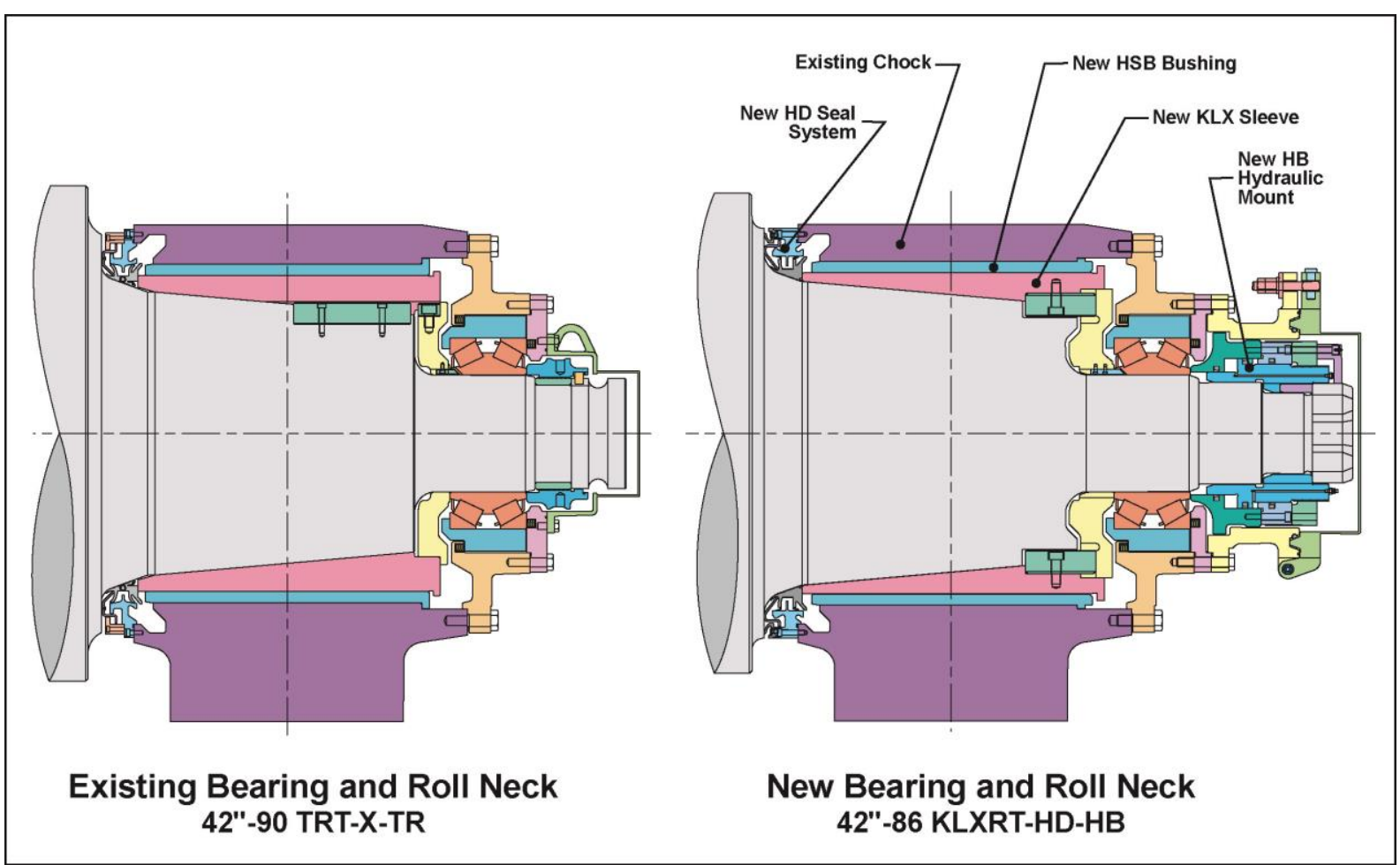

Fig. 4: Comparison of Existing verses Upgraded Bearing.

\section{Upgrade details:}

\section{Sleeve}

Since the maximum load increase was needed along with improved strip quality, it was determined this conversion should be an upgrade to the MORGOIL $®$ KLX $®$ bearing, Figure 5. The KLX bearing uses the latest technology thin sleeve design allowing for larger roll necks and higher unit loading. This conversion requires new rolls and bushings, but the increase in capacity can be up to $45 \%$ over a $\mathrm{T}$ type bearing (under certain conditions and including other improvements). The new rolls are needed to cope with neck stress because of the large rating increase.

If an upgrade is needed, but not the full capacity of the KLX, the original MORGOIL long key $\mathrm{T}$ type bearing can be converted to a KT, or short key design sleeve, Figure 5. This common conversion effectively eliminates keyway effect along with allowing an $18 \%$ increase in load rating of the bearing. This conversion can use the existing rolls with new keyways while filling the old keyways.

These conversions are particularly attractive for older mills, where the mill operators want to bring a mill's capabilities up to that of a new mill, but don't want the cost of a new mill. 


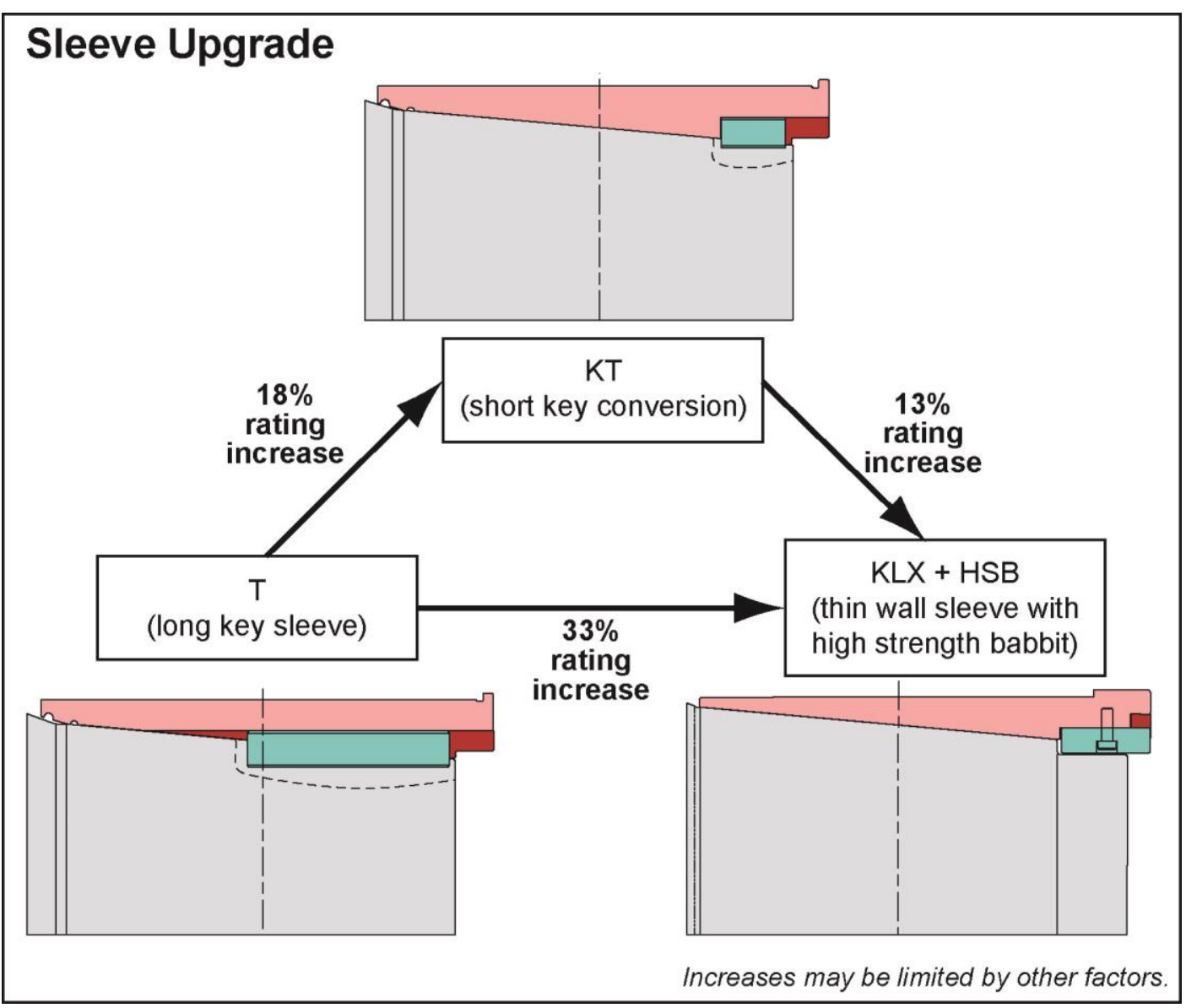

Fig. 5: Sleeve Upgrade Path

\section{Bushing}

This conversion also helped bearing rating increase through the use of High Strength Babbitt (HSB) bushings, Figure 6. High Strength Babbitt can also be used as a viable substitute for cadmium bushings. Through the use of a short key conversion of the sleeve combined with High Strength Babbitt bushings ratings can be significantly increased. Upgrading old $\mathrm{T}$ bearings to special short key sleeves and HSB bushings can increase the rating by up to $33 \%$. 


\section{Bushing Upgrade}

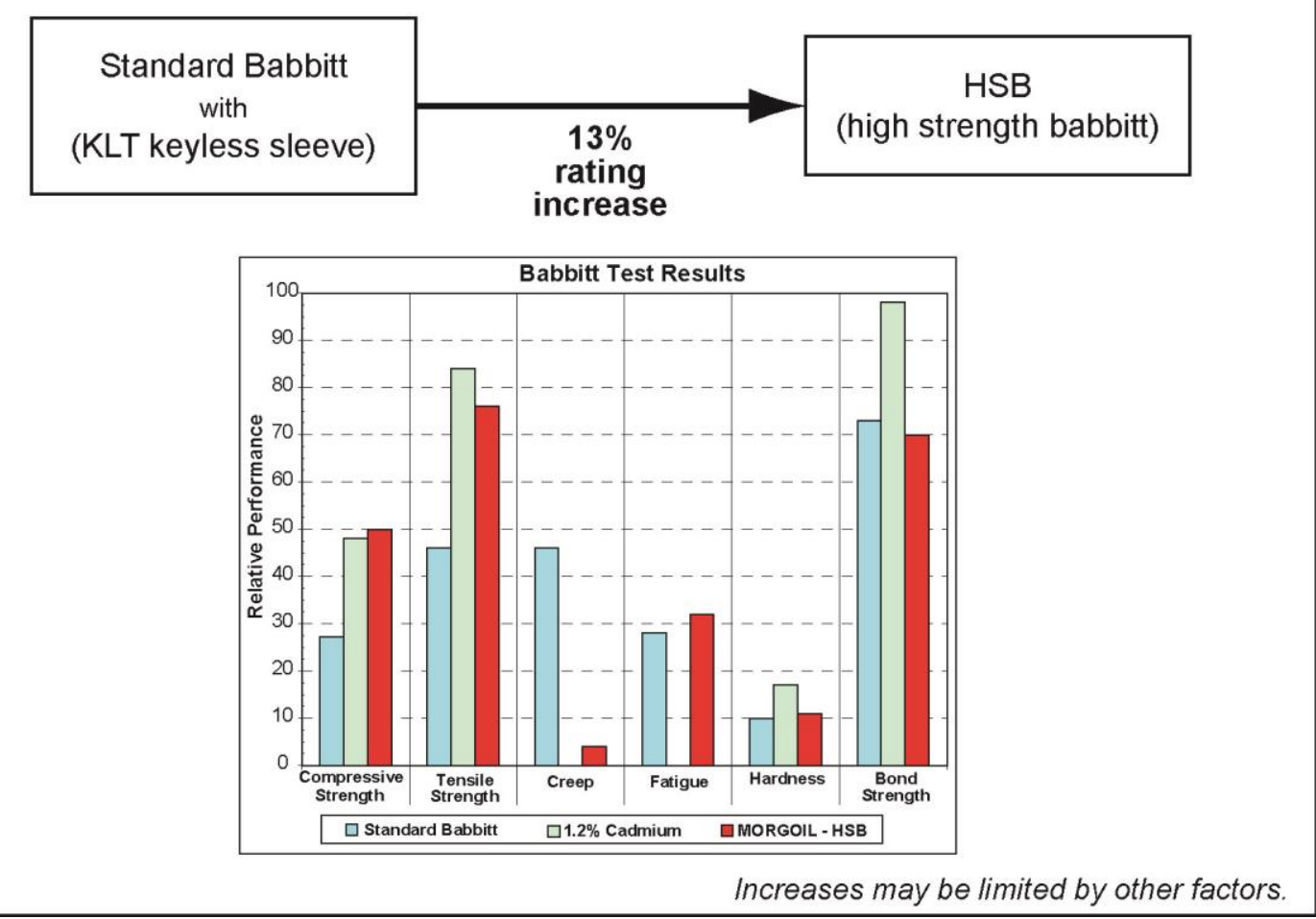

Fig. 6: Bushing Upgrade Path

\section{Locking}

This upgrade includes a change in locking technology. The original Threaded Ring (TR) design has been replaced by an Hydraulic Bayonet Lock (HB), figure 7. This lock increases the repeatability and speed of the locking process and eliminates the need to use an overhead crane to tighten the locks. Additionally, this lock reduces operator effort and increases safety.

The HB conversion requires new rolls or bolt-on roll ends. If existing rolls are being used, the HM or LD lock can be used as an alternative, although they don't have the full convenience of the HB. 


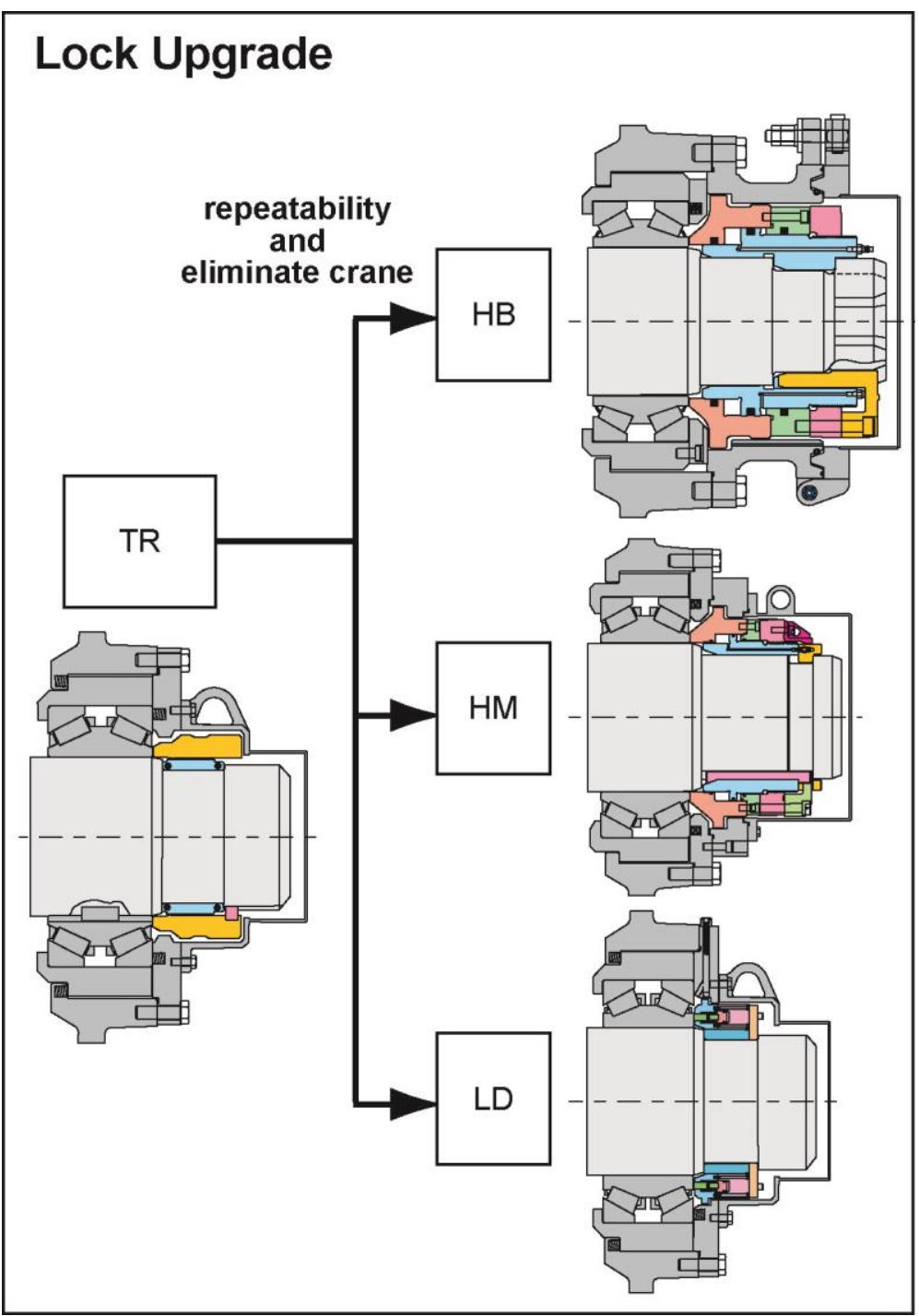

Fig. 7: Lock Upgrade

\section{Sealing}

As with the other major areas of the bearing, the sealing system has also seen several changes over the years. This conversion uses the latest developments in sealing, the HD Sealing System, Figure 8. It consists of the HD seal and ceramic coated seal end plate. The seal end plate also includes the latest drainback and venting features. The system also has a coolant guard. 


\section{Seal Upgrade}

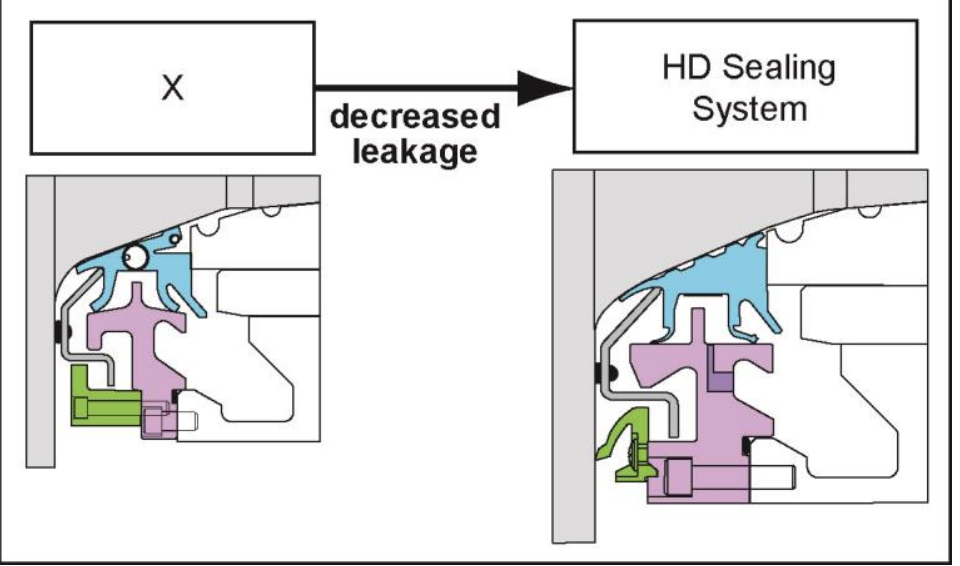

Fig. 8: Seal Upgrade

\section{CONCLUSION}

Upgrades, strategically planned between the mill operator and equipment supplier, can extend the life of a mill far into the future. In this case, Ternium-Siderar and MOROGIL® Bearings worked together to bring a decades old mill up to modern standards in an economical and operationally friendly manner.

Conversions such as this help older mills compete with the quality of new mills and remain highly cost effective. In many of these cases, mills have paid for the upgrade within a year through increased productivity and more efficient utilization of mill equipment.

The case study described how a complete bearing upgrade is a cost effective solution when large capacity increases are required in existing space. In the case of the Ternium-Siderar HSM, a complete MOROGIL® KLX® conversion of their finishing stands allows the use of rolls with larger necks, with the result of eliminating a roll neck breakage problem.

With appropriate back-up roll bearing upgrades, mills can increase capacity, allowing them to roll products that were not even considered before. Older oil film bearings and roller bearings have been successfully upgraded while reusing existing chocks and in many cases rolls.

This conversion upgraded all aspects of the bearing. The best performance increases come when doing it like this. However, if it is not feasible to perform a full upgrade, individual problem areas can be upgraded separately. 